Open Scientist Handbook • OSH

\title{
A guide for scientists to become culture change agents for open science
}

Bruce R. Caron

Published on: Mar 03, 2021

DOI: $10.21428 / 8 b b b 7 f 85 . b 1 d 754 c 8$

License: Creative Commons Attribution 4.0 International License (CC-BY 4.0). 


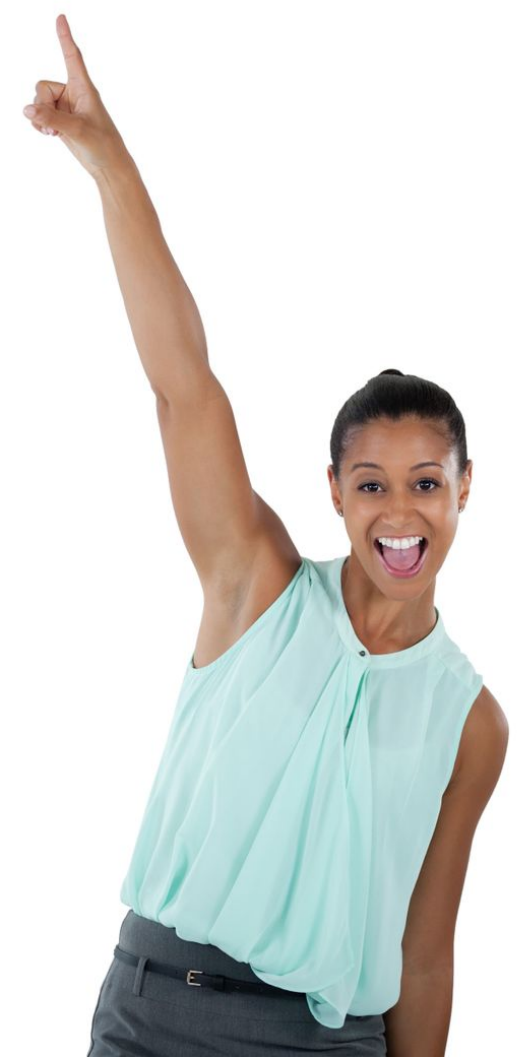

"I believe that by focussing our attention on communites [sic], groups, clubs and the incentives that they work within we will make more progress, because at some level the incentives for the group are the culture" (Neylon 2015; Accessed June $25,2019)$.

\section{Open science needs you to become a culture change agent.}

Almost everybody you can talk with might agree that changing culture is hard to do. Even getting your arms around the word "culture" is difficult, as we will see later in this chapter. What is becoming more obvious, in this, the opening innings of the $21^{\text {st }}$ century, is that stopping culture from changing is even harder in our daily lives. Outside our jobs, we swim in world-wide jet streams of cultural ideas, and cultureinformed gadgets and all the stuff we now buy at Amazon (there's a cultural shift for you, too). Older cultural orders, such as religions and nation-states, struggle to stay current with their traditional messages. 
At the same time, adopting to a new technology is often seen as trivial. We live in a stream of continuous small and large technology changes, from the internet, cell phones, and cloud services, to machine learning and artificial intelligence. We integrate these new technologies into our lives and our work as a normal course of how we operate, personally and professionally.

We spend time in new ways, connecting on social networks, joining teleconferences, editing shared documents and code, sharing ideas, photos, videos, emotional moments, personal triumphs and dead pets. How hard is it to sign up for a new platform and start sharing stories, car rides, or spare bedrooms? Not very hard at all. Today. Today, much of what we do and use was impossible until the moment it became inevitable, like Wikipedia.

Here's the secret: every single one of these technologies that we've integrated into our lives has also changed our culture: the shared practices we use to learn and communicate the knowhow (and the know-where, and know-when) that technology requires to be used. A lot of culture change is just this easy. At the same time, it's really important to note that a great part of these changes involve commercial technology platforms teaching us to become better users for their purposes; optimizing the world around their needs, instead of ours, to achieve an optimal state for their growth (See: Lanier 2014). In this case it's not so much that we are changing culture, but rather some new variant of techno-culture is changing us.

Perhaps this is one reason some open-science promoters are hoping that all the new open-science technology platforms can simply remake us into "open scientists," or that, when we are presented with a list of the benefits that open sharing opportunities create for the academy, we will rationally choose to hop on the open-science wagon. As if that's all we need to do. 


\section{You can make your workflow more open by ...}

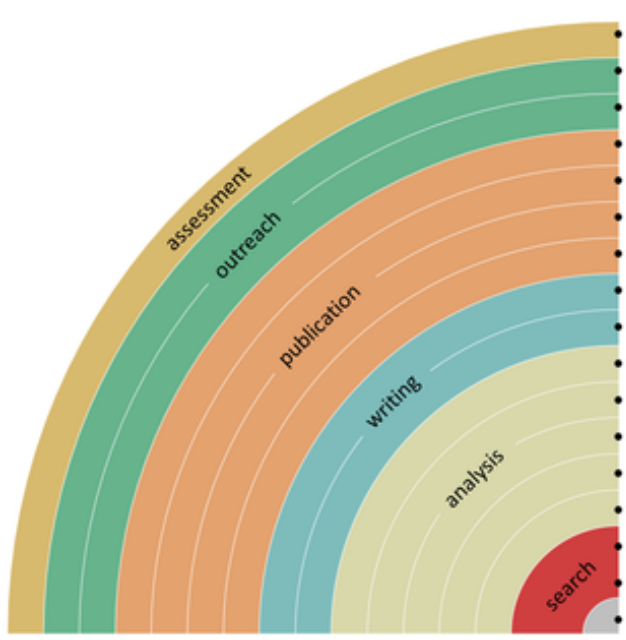

@- 1 - Bianca Kramer \& Jeroen Bosman https://101innovotions, wordpress.con adding alternative evaluation, e.g. with altmetrics communicating through social media, e.g. Twitter sharing posters \& presentations, e.g. at FigShare using open licenses, e.g. CCO or CC-BY publishing open access, 'green' or 'gold' using open peer review, e.g. at journals or PubPeer sharing preprints, e.g. at OSF, arXiv or bioRxiv using actionable formats, e.g. with Jupyter or CoCalc open XML-drafting, e.g. at Overleaf or Authorea sharing protocols \& workfl., e.g. at Protocols.io sharing notebooks, e.g. at OpenNotebookScience sharing code, e.g. at GitHub with GNU/MIT license sharing data, e.g. at Dryad, Zenodo or Dataverse pre-registering, e.g. at OSF or AsPredicted commenting openly, e.g. with Hypothes.is using shared reference libraries, e.g. with Zotero sharing (grant) proposals, e.g. at RIO

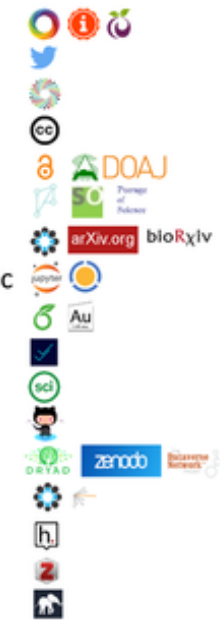

DOI: $10.5281 / 2$ enodo. 1147025

Infographic on how to make your workflow more "open." Note: this infographic is years old, and does not represent the current state of thinking about "open." It demonstrates how platforms were/are being set up as solutions instead of tools. DOI: 10.5281/zenodo.1147025

“The culture of today's research universities is built from elements of past universities, including the medieval roles and responsibilities of faculty, the 1819 th century structure of departments, and the mid-20th century research funding model." (Katz et al. 2018)

Universities already carry around a lot of historical cultural baggage, and are said to carry a profound sentiment for resisting change. "Traditions" that uphold hierarchies and concentrate power and decisions at the top are difficult to challenge from below. These need to be challenged in any case. Hundreds of open-research projects happening today across the globe are sharpening the attack.

Actually, many of the "traditions" in play today are not actually old, but rather, they reflect compromises cobbled together in prior decades to corral the growth of universities within layers of neoliberal management. “...[S]ince the eighties, Ginsberg [2011] argues, university administrators have effectively staged a coup. They wrested control of the university from the faculty and oriented the institution itself toward entirely different purposes. It is now commonplace for major universities to put out 'strategic vision documents' that barely mention scholarship or teaching but go on at 
length about 'the student experience,' 'research excellence' (getting grants), collaboration with business or government, and so forth" (Graeber 2019).

This means, of course, that these neoliberal "traditions" mainly insinuated themselves into university cultures since World War II, which suggests they can be similarly removed through intentional cultural change tactics: through recalling and reinstating prior practices (older traditions of scientific norms and sociability-a kind of "retraditionalization" that might also be attractive to conservative culture-change skeptics); and/or replaced with practices that embrace new technologies and social justice. The point is that many of the most fiercely held traditions in the academy are not old, and are the outcomes of recent cultural changes; they are likewise open to change. In fact they are ripe for change.

"Currently, the vast majority of the science pie rewards the building of empiresthat is, the model that has scientists clambering over one another to reach the top" (Steeves 2018, Springer Nature Careers, January 18).

\section{Real change starts with intention}

If technology really can change our culture for its use, then using these platforms and services can help by supporting new cultural behaviors. But the real change we need to focus on is changing the intention that we, and our colleagues bring to our research. It is intent that can make an action kind or unkind; intent that colors how and why we share our research; and intent that is capable of moving the academy away from the perverse incentives that now toxify its culture. Technology alone cannot be expected to provide the cultural anchor for new, open-science behaviors.

\section{Bibliography: Open Scientist Handbook References}

